\title{
PREVENÇÃO AO ABUSO DE DROGAS NA PRÁTICA PEDAGÓGICA DOS PROFESSORES DO ENSINO FUNDAMENTAL ${ }^{a}$
}

\author{
Prevención del abuso de drogas en la práctica pedagógica de la enseñanza general básica
}

\section{Drug abuse prevention in pedagogical practices of basic education teachers}

Ingryd Cunha Ventura FE LIPE

Gertrudes T eixeira LOPESc

O livro escrito pela pedagoga M arília Saldanha da Fonseca deriva de sua T ese de D outoramento em E ducação pela U niversidade Estadual de Campinas. 0 texto é didático e bastante conciso no decorrer dos sete capítulos divididos em 252 páginas. $\mathrm{N}$ a introdução apresenta a contextualização do fenômeno das drogas no mundo e principalmente no Brasil, o uso de drogas na história das civilizações destacando dados epidemiológicos de pesquisas já realizadas.

0 objetivo do estudo foi pesquisar se as atuais práticas docentes em educação preventiva atendem às demandas sociais de abuso de drogas entre estudantes e, se não for o caso, buscar alternativas metodológicas para novas práticas preventivas concebidas e organizadas pel os professores, nas condições do contexto social existente.

Diante da problemática do estudo, apresenta-se uma descrição consistente sobre drogas nas escolas, abrangendo conceitos, classificação, legislação e prevenção. A mplia a discussão sobre saúde/ doença, com suas significações e paradigmas, abarca questões de promoção da saúde, componentes de prevenção primária, fatores de proteção, vulnerabilidade e resiliência. A obra incorpora a análise dos fundamentos da educação preventiva e traça uma proposta de delineamento para a educação, cuja ênfase ancora nos princípios da prevenção ao abuso de drogas na prática docente como um dos principais instrumentos para buscar as ações preventivas.

Portanto, foi realizada uma intervenção pedagógica juntamente com professores de uma escola pública fundamental, elaborando proposta pedagógica sistematizada através de encarte, mostrando a inclusão dos conteúdos nas disciplinas. A proposta abre perspectivas para que seja implementado em outras escolas do País.

Ponto alto do presente trabalho é a crítica que a autora faz aos modos atuais de prevenção realizados nas escolas, cuja forma se configura como incipiente, retratando a defasagem na formação de professores para o ensino fundamental e levantando questões de saúde inerentes à escolas e alunos.

Por fim, o trabalho não esgota os aspectos de prevenção ao abuso de drogas, no entanto apresenta possibilidades para implantação da prevenção nas escolas. M ostra na prática educacional como traçar projetos integrados entre escola, professores, alunos e comunidades ampliando ações voltadas à saúde do escolar e a formação continua do professor, com ênfase na prevenção ao abuso de drogas.

\footnotetext{
a Resenha da obra: Fonseca M S. Prevenção ao abuso de drogas na prática pedagógica dos professores do ensino fundamental. São Paulo: Blucher A cadêmico; 2008.

${ }^{b}$ M estre em E nfermagem, E specialista em E nfermagem do T rabal ho, D outor anda em E nfermagem pela F acul dade de E nfermagem (F E N F ) da U niversidade do Estado do Rio de Janeiro (UERJ), M embro do Grupo de Estudos e Pesquisas em Álcool e outras D rogas (GEPAD) da FENF/UERJ, Rio de Janeiro, Brasil.

c Pós-D outorada em Á Icool e outras D rogas, Professora T itular do D epartamento de F undamentos de E nfermagem da U ERJ, Pesquisadora do Conselho N acional de Desenvolvimento Científico e T ecnológico (CN Pq) e da F undação de A mparo à Pesquisa do E stado do Rio de Janeiro (FAPERJ), M embro do GEPAD da FENF/ UERJ, Rio de Janeiro, Brasil.
} 
De todos os modos, a leitura deste livro incita-nos a acreditar que o enfermeiro, atuando na prevenção de álcool e outras drogas, encontre material suficiente para a construção de novos saberes em sua área de conhecimento, uma vez que as informações e os dados específicos contidos na área de educação, bem como as propostas incorporadas dão sustentação às intervenções no âmbito da escola. 